\title{
Study and suggestions on Co-benefits of reduction in greenhouse gas emissions and air pollution control
}

\author{
Jianfang Zong, ${ }^{*}$, Mei Liu, Liang Sun, Huiting Guo \\ China National Institute of Standardization \\ No.4 Zhichun Road, Haidian district, Beijing, 100191
}

\begin{abstract}
Studying the co-benefits of greenhouse gases and air pollutants is highly relevant as China tries to cope with the dual challenges of climate change and pollution control. Over the past ten years, plenty of studies at home and abroad have paid attention to these co-benefits, including policy analysis, model application, case discussion, etc., and various co-benefit theories have been introduced to lay a solid scientific foundation for the development of energy and environmental development policies. In this paper, different definitions and types of co-benefits are provided, and co-benefit evaluation methodology is explained. International and domestic progress in studies on the co-benefits of reduction in greenhouse gas emissions and air pollution control are elaborated, and prospects and suggestions on future studies are analyzed.
\end{abstract}

\section{Introduction}

Co-benefit, also known as ancillary benefit and secondary benefit, was first proposed by German scientist Herman Haken. It refers to involuntary and added benefits from a policy or after a policy is implemented, other than the direct benefits expected during the inception of design [1]. In the general sense, co-benefits are not neutral; they specifically refer to policy outputs or benefits that are positive. Co-benefits run through all aspects of policy implementation and reflects the thinking of holistic management: In a narrow sense, when a policy is evaluated by the measure of costeffectiveness, co-benefits provide a method to comprehensively measure the net cost of a policy. In a broader sense, co-benefits can be essentially extended to all aspects of natural, social and economic systems. It echoes the concept of sustainable development. The study on co-benefits is of significance to the implementation of sustainable development strategy in China.

Now, co-benefits are often cited in discussions on emission reduction of greenhouse gases (GHGs) and local air pollutants. The Intergovernmental Panel on Climate Change (IPCC) has a clear definition of cobenefits of GHG reduction [2]: co-benefits are quantitative results of the monetization of added benefits after the implementation of a GHG reduction policy, such as reduced emissions of local air pollutants due to less use of fossil fuels and indirect positive impacts on energy security and employment. GHGs and local air pollutants mainly come from the utilization process of carbon-based fossil energy. This "common source" mainly explains why their co-benefits are widely discussed. Therefore, no doubt co-benefits of reduced air pollutants can be generated by controlling GHG emissions associated with energy production, conversion, and utilization activities, especially carbon dioxide emissions. Co-benefits can and should be explored in the integrated management of energy, environment and climate change. No consensus has been reached on the definition of co-benefits. Definitions provided by some international agencies are similar on one hand and have different focuses on the other, as shown in Table 1.

For some time to come, China will still experience rapid industrialization and urbanization processes. At the same time, it will find itself under increasing pressure to cope with climate change and air pollutant control. China has taken measures in energy conservation, carbon reduction and pollution control, and a complete control and governance system that defines aggregate and intensity constraint targets and specific measures has been established. Take the energy sector as an example [3]. During the "Thirteenth Five-Year Plan" period, the total energy consumption will be controlled within 5 billion tce, and the energy consumption per unit of GDP will be reduced by more than $15 \%$. Various specific measures will be taken to achieve the aggregate and intensity control targets in the structural reform on the energy supply side and energy consumption revolution. However, this governance system targets at energy conservation and carbon reduction as well as air pollution control separately. The design of policy measures, reflected in whether the setting of targets or the specific action plan, does not allow for the evaluation of the comprehensive impact of GHG and air pollutant emissions or their co-benefits. Considering the significance of co-benefits to development decision-

\footnotetext{
* Corresponding author: zongjf@enis.ac.cn
} 
making, studies are necessary in that they can explore the incorporation of co-benefits to the policy framework and the integrated management of energy, environment and climate change based on their co-benefits [3].

Table 1 Definitions and illustrations of Co-benefits by international agencies

\begin{tabular}{|c|c|c|}
\hline Agency & Time & Definition or Illustration \\
\hline $\begin{array}{l}\text { Intergovernment } \\
\text { al Panel on } \\
\text { Climate Change } \\
\text { (IPCC) }\end{array}$ & 2001 & $\begin{array}{l}\text { According to the Third } \\
\text { Assessment Report, co- } \\
\text { benefits refer to non- } \\
\text { climate change mitigation } \\
\text { benefits that are clearly } \\
\text { mentioned as additional } \\
\text { motives in the design and } \\
\text { implementation of } \\
\text { greenhouse gas mitigation } \\
\text { policies. }\end{array}$ \\
\hline $\begin{array}{l}\text { Organization for } \\
\text { Economic Co- } \\
\text { operation and } \\
\text { Development } \\
\text { (OECD) }\end{array}$ & 2009 & $\begin{array}{l}\text { There is a potentially } \\
\text { large and diverse range of } \\
\text { collateral benefits that can } \\
\text { be associated with climate } \\
\text { change mitigation policies } \\
\text { in addition to the direct } \\
\text { avoided climate impact } \\
\text { benefits. Depending on } \\
\text { the context, mitigation } \\
\text { actions targeting clean } \\
\text { energy technologies or } \\
\text { energy efficiency, for } \\
\text { example, are likely to } \\
\text { include improvements in } \\
\text { local or in indoor air } \\
\text { quality which in turn limit } \\
\text { risks to human health. } \\
\text { These collateral benefits } \\
\text { are referred to here as } \\
\text { "co-benefits" of climate } \\
\text { change mitigation policies } \\
\text { [4]. }\end{array}$ \\
\hline $\begin{array}{l}\text { US } \\
\text { Environmental } \\
\text { Protection } \\
\text { Agency (U.S. } \\
\text { EPA) }\end{array}$ & 2004 & $\begin{array}{l}\text { The ancillary or } \\
\text { additional benefits of } \\
\text { policies that are } \\
\text { implemented with a } \\
\text { primary goal, such as } \\
\text { climate change mitigation } \\
\text { - acknowledging that } \\
\text { most policies designed to } \\
\text { reduce greenhouse gas } \\
\text { emissions also have other, } \\
\text { often at least equally } \\
\text { important, benefits (e.g., } \\
\text { energy savings, economic } \\
\text { benefits, air quality } \\
\text { benefits, public health } \\
\text { benefits). Also referred to } \\
\text { as "multiple benefits" [5]. }\end{array}$ \\
\hline $\begin{array}{l}\text { European } \\
\text { Environment } \\
\text { Agency (EEA) }\end{array}$ & 2007 & $\begin{array}{l}\text { Mitigation measures can } \\
\text { also have other benefits } \\
\text { for society, such as health } \\
\text { cost savings resulting } \\
\text { from reduced air pollution } \\
\text { [6]. }\end{array}$ \\
\hline $\begin{array}{l}\text { The Ministry of } \\
\text { the Environment }\end{array}$ & 2008 & $\begin{array}{lr}\text { Co-benefits } & \text { in } \\
\text { environmental } & \text { pollution }\end{array}$ \\
\hline
\end{tabular}

\begin{tabular}{|c|c|c|}
\hline $\begin{array}{ll}\text { of } & \text { Japan } \\
(\mathrm{MOEJ}) & \end{array}$ & & $\begin{array}{l}\text { control can help } \\
\text { developing } \\
\text { reduce greenhouse gas } \\
\text { emissions and make } \\
\text { progress [7]. }\end{array}$ \\
\hline $\begin{array}{l}\text { Policy Research } \\
\text { Center for } \\
\text { Environment } \\
\text { and Economy, } \\
\text { the Ministry of } \\
\text { Ecology and } \\
\text { Environment of } \\
\text { the People's } \\
\text { Republic of } \\
\text { China (PRCEE) }\end{array}$ & 2004 & $\begin{array}{l}\text { On the one hand, co- } \\
\text { benefits include reduced } \\
\text { emissions of other local } \\
\text { pollutants, such as SO2, } \\
\text { NOx, CO, VOC, and PM, } \\
\text { along with the control of } \\
\text { greenhouse gas emissions. } \\
\text { On the other hand, co- } \\
\text { benefits also include } \\
\text { reduction or absorption of } \\
\mathrm{CO} 2 \text { and other } \\
\text { greenhouse gas emissions } \\
\text { in addition to the control } \\
\text { of local pollutant } \\
\text { emissions and during } \\
\text { ecological construction. }\end{array}$ \\
\hline
\end{tabular}

\section{Classification of Co-benefits}

Most of the studies on co-benefits of GHG and air pollutant control focus on climate policies, which is thus the basis for the classification of co-benefits in this section. As shown in Table 2, co-benefits of climate policies are classified by quantitative/qualitative assessment, and quantitative assessment is classified into physical quantification/economic quantification.

Table 2 Main types of Co-benefits of climate policies

\begin{tabular}{|c|c|c|}
\hline \multicolumn{2}{|c|}{ Quantitative Studies } & \multirow{2}{*}{$\begin{array}{l}\text { Qualitative } \\
\text { Studies }\end{array}$} \\
\hline $\begin{array}{l}\text { Physical } \\
\text { quantification }\end{array}$ & $\begin{array}{l}\text { Economic } \\
\text { quantification }\end{array}$ & \\
\hline $\begin{array}{ll}\text { Reduced } & \\
\text { emissions } & \text { of } \\
\text { local air } & \text { air } \\
\text { pollutants } & \end{array}$ & $\begin{array}{lr}\text { Avoidance } & \text { of } \\
\text { control costs } \\
\text { due to reduced } \\
\text { emissions of } \\
\text { local rair } \\
\text { pollutants }\end{array}$ & $\begin{array}{l}\text { Stimulation of } \\
\text { technological } \\
\text { innovation, } \\
\text { technological } \\
\text { substitution, etc. }\end{array}$ \\
\hline $\begin{array}{l}\text { Reduced } \\
\text { ecosystem } \\
\text { damage } \\
\text { (comprehensi } \\
\text { vely } \\
\text { characterized } \\
\text { by indicators } \\
\text { such as acid } \\
\text { rain and } \\
\text { eutrophicatio } \\
\text { n) }\end{array}$ & $\begin{array}{l}\text { Health benefits } \\
\text { [monetized by } \\
\text { Willingness to } \\
\text { Pay (WTP) or } \\
\text { human capital } \\
\text { approach] }\end{array}$ & $\begin{array}{l}\text { Enhanced energy } \\
\text { security (increased } \\
\text { energy diversity } \\
\text { and reduced } \\
\text { energy } \\
\text { dependency) }\end{array}$ \\
\hline $\begin{array}{l}\text { Health } \\
\text { benefits } \\
\text { (characterized } \\
\text { by morbidity } \\
\text { rate or } \\
\text { mortality } \\
\text { rate) }\end{array}$ & $\begin{array}{l}\text { Positive effects } \\
\text { on employment } \\
\text { (measured as } \\
\text { changes in } \\
\text { GDP) }\end{array}$ & $\begin{array}{l}\text { Positive impact on } \\
\text { employment }\end{array}$ \\
\hline
\end{tabular}

Of all the types of co-benefits listed in Table 2, reduced emissions of local air pollutants due to the implementation of climate policies are the most concerned co-benefits [8-10]. The physical quantities of 
reduced local air pollutants are of high policy significance in countries or regions where the aggregate air pollution control mode is adopted. Associated health benefits on the basis of reductions can be further evaluated. Statistics show that health benefits are the most important co-benefits that account for more than $80 \%$ of all co-benefits of climate policies. The health benefits are quantitatively measured with the Air-health Pathway. Characteristic indicators of health benefits include endpoint physical quantities of health effect evaluation, such as mortality rate, loss of life, and rate of seeing a doctor [11], and quantities of money measured by equivalent valuation methods such as WTP/human capital approach [12-15]. However, the results of health benefit evaluation are not reliable and credible enough, because both the methods and parameters are highly uncertain. For example, the selected evaluation endpoints cannot fully and accurately reflect the health impact of pollutants, and the sample surveys to support environmental valuation is underrepresented [16].

Another way to economically quantify the reduction of air pollutants is to calculate the control cost avoided by the reduction, and this is a common approach in EU studies [17-20]. However, because the evaluation results from this approach rely heavily on the model and scenarios adopted by the researcher, the reduction in air pollution control cost varies greatly among studies. According to Van Vuuren, Cofala, and Eerens, the reduced cost of air pollutant cut as a result of EU's participation in the Kyoto Protocol accounted for about half of the cost of climate policy implementation. Under the same research context, Nathan [19] found that the cost savings accounted for only $0.2 \%$ to $3.9 \%$.

In addition, a few studies further comprehensively evaluated the impact of air pollutant emissions on global or regional ecosystems. Among typical air pollutants, $\mathrm{SO} 2$ is the main contributor of acid rain that harms the ecological environment in such ways as soil acidification, water loss and soil erosion, and forest reduction; NOx leads to eutrophication and further unbalanced nitrogen cycle. The RAINS (Regional Air Pollution Information and Simulation) model designed and developed by the International Institute for Applied System Analysis (IIASA) has been the most mature and widely used model system to assess various ecological and environmental effects of different air pollutants to date [21].

Furthermore, co-benefits of climate policies to economy and society are also analyzed in some studies. The economic benefits are often measured by carbon tax [22], and social co-benefits are multifaceted, such as improved solid waste management [23], enhanced energy security [24], less congestion in highways, agricultural growth [25], employment influence and technology facilitation [26]. Economic and social impacts are mainly measured with quantitative methods, due to inconsistent and immature physical or economic quantification approaches.

The physical quantities (reduction in air pollutants, comprehensive impact on the ecological environment) and economic quantities (health benefits, avoidance of control cost) of co-benefits have different advantages in assisting in policy making: the former can be combined with regional goals of ecological environmental protection conveniently and the direct result of ecological environmental protection is a catalyst to arouse public awareness; the latter is economically oriented for the assessment of policy cost-effectiveness and can be taken into consideration with regional macroeconomic policies [27].

\section{Methodology of Co-benefit evaluation}

\subsection{Greenhouse gas - Air pollution interaction and synergies (GAINS)}

GAINS has been used all over the world as a co-benefit quantitative model developed by the IIASA. Its applications include economic statistics, energy and agricultural planning, and emission inventories in typical regions. GAINS can be used to simulate emission scenarios of all major air pollutants resulting from a given economic activity to be applied and estimate the potential and cost of emission reduction, with the interactions of reduced emissions from various pollutants taken into account. The GAINS model tracks pollutants from driving sources (such as energy consumption, industrial activities, and agricultural production) while allowing for the characteristics of emissions from different sources and regions. It then analyzes the potential of emission reduction through a wide range of technical and non-technical measures, estimates the cost of emission reduction, and calculates the impact indicators of GHG emissions, human health, and ecosystems.

\subsection{Integration of environmental strategy (IES) of EPA}

IES is a framework that analyzes co-benefits by combining necessary models with tools. It is often used to quantify the co-benefits of GHG reduction and air pollution control in the environment (including air quality and GHGs), public health, and economy. An IES project include a series of steps, including building a project team, developing energy/emission scenarios, calculating atmospheric concentrations, quantifying the impact on public health, assessing the economic value of health benefits, ranking various measures and results, and taking measures.

\subsection{Energy-environment-economics (3E) model for quantification of Co-benefits}

GHG and pollutant control policies are concerned about the comprehensive, balanced, and coordinated development of energy, economics, and environment. Therefore, quantitative studies usually adopt a model system that covers all of these subsystems. This type of model is called the Energy-Economics-Environment (3E) model which is a major method to measure co-benefits. Depending on micro or macro modeling, the $3 \mathrm{E}$ model is 
divided into bottom-up, top-down, and hybrid types. Since they have different characteristics, they suit different subjects and yield different calculation results when applied in co-benefit studies.

\section{Studies on the Co-benefits of reduction in GHG emissions and air pollution control}

\subsection{Progress in foreign studies}

Co-benefit studies started early in foreign countries and dated back to the late 1990s or so. Studies in Europe, the United States, and Japan are relatively comprehensive and extensive. They are mostly characterized by the use of models, and the development of such models is mature. Mature models and reasonable scenario analysis method together push quantitative studies on the topic to a high level. Most of these studies focus on the cobenefits of climate change policies as well as their health and social benefits, and are committed to measuring them through monetization or quantification. These studies are also extensive, conducted at global, national and city levels and covering extremely diverse sectors.

(1) Studies on cost Co-benefits

Studies on cost co-benefits focus on the co-benefits in reduced emissions of traditional pollutants as a result of GHG reduction measures intended to deliver cost and health benefits through model simulations. Bollen et al. applied the MERGE model in a cost-benefit analysis on GHG reduction policies and pollution control measures [28]. Petter Tollerfsen et al. Applied the Regional Acidification Information and Simulation (RAINS) model to evaluate the climate cost of air pollutants and generate the co-benefits of reducing air pollutant emissions to cope with climate change [29]. Rive applied the CGE model in a study on the reduced cost of pollution control with the intervention of climate policy in Western European countries [30]. Rafaj et al. applied the GAINS and global energy system models to study the impact of global GHG policies on traditional air pollutants and quantify the pollution control cost and the health and the environmental impact [31]. Chae studied the co-benefits of the air quality management plan and the GHG reduction program in Seoul, South Korea, and calculated the cost-effectiveness of each project [32].

(2) Studies on Materialized Co-benefits

There are few studies on materialized co-benefits, and they mainly analyze the co-benefits of policies coping with GHG reduction and air pollutant control. Shrestha et al. studied the co-benefits of policies coping with GHG reduction and air pollutant control in Thailand under the Markal model [33].

\subsection{Progress in domestic studies}

Co-benefit studies started relatively late in China and did not appear until about 2003. Compared with those of international scholars, the studies in China are still limited by the use of emission reductions as the single evaluation criterion. Most of them focus on evaluating the co-benefits of emission reduction measures supported by engineering technologies in a city or industry, and few of them adopt energy or economic models to quantify other co-benefits (such as public health benefits and social benefits) and the economic cost of collaborative emission reduction. Given the national situation where the reduction in pollutant emissions attract more attention, domestic scholars focus more on the co-benefits of pollution control policies than on those of GHG control policies.

(1) Qualitative studies

Tao $\mathrm{Hu}$ et al. indicated that the co-benefits of environmental improvements and GHG reduction will have an impact on the climate change and environmental policies in China, especially pollution control and ecological construction policies [34]. Liping Li et al. examined a co-benefit plan based on total emission reduction realized by three measures of "engineering emission reduction", "structural emission reduction", and "management emission reduction". The result showed that different emission reduction technologies and measures lead to different co-benefits: positive cobenefits mainly come from "structural emission reduction", while negative ones mainly come from "engineering emission reduction" [35].

(2) Quantitative studies

Quantitative studies focus on simulating and evaluating the costs, health benefits or materialized cobenefits in different scenarios at the regional or industry level by applying a model. Changhong Chen et al. applied the Markal model to predict energy consumption and air pollutant emissions in the basic scenario and the energy policy scenario [36]. He et al. applied the LEAP model to predict energy consumption in China in different scenarios, estimate pollutants and GHGs, monetize and compare the benefits of $\mathrm{CO} 2$ emission reduction and health benefits [37]. Yuanbo Xie applied the LEAP model to predict the emission reduction effects of major air pollutants and GHGs in Beijing for 2010-2020 in three scenarios [38]. Xianqiang Mao combined the $3 \mathrm{E}$ model with a case study of the thermal power industry and proposed a method to evaluate the co-benefits of technological emission reduction measures [39].

\section{Prospects and suggestions on future Co-benefit studies}

\subsection{Expand the coverage of Co-benefit analysis to meet the needs of ecological civilization construction and sustainable development}

Because energy consumption is naturally associated with GHG and air pollutant emissions, most of co-benefit studies focus on their relationships. However, controlling GHG and air pollutant emissions is simply part of ecological environmental protection. Ecological civilization construction and social sustainable development call for wider implications of co-benefit studies. Specifically, the coverage of co-benefits should 
evolve from reduced pollutant emissions at the primary level to reduced emissions and adaptation at the high level. At the primary level, the focus should be extended from air pollution to water, soil and other pollution. For example, some industries, such as the chemical industry and the papermaking industry, are faced with noticeable problems of high energy consumption, air pollution and water pollution discharge. At the intermediate level, the focus should be extended from pollution issues to resource issues, and the synergy of energy with water resources and land resources can be explored. To examine resource constraints, the focus should be laid on promoting coordinated spatial distribution of various energy sources and resources. At the high level, the focus should be extended from emission reduction to adaptation. Attaching equal importance to emission reduction and adaptation is the key to coping with climate change, protecting the ecological environment, and achieving energy/water security. Because adaptation activities are concentrated in farmland, water, forests and other natural ecosystems, in-depth studies on resource issues at the intermediate level is essential to the building of adaptability and fundamental to adaptation studies.

\subsection{Improve Co-benefit research methodology to fully and effectively assist policy making}

Currently, co-benefit studies in China are not able to effectively support policy making partly because the relevant methodology is not sound enough, and especially there is large modeling gap to fill with foreign countries. Domestic studies mostly borrow mature models and embedded parameters from other countries. However, these model systems and supporting data do not match the status quo in China because they are generally based in Europe and the United States. Therefore, in terms of model development, we should, first of all, establish model frameworks and database platforms based on the current technology applications and economic operations in China. The next step is to further explore improvements in the model architecture, including building a hybrid model that reflects interactions between energy, economy, and environment sectors as well as rich technical details; more integrated model systems that allow for intricate coupling relationships between industries, such as upstream and downstream production and technology matching may be developed; the ability of the models to interpret policies can be enhanced through technical means such as the Monte Carlo uncertainty analysis, the game theory, and the technology diffusion theory. In addition, more and innovative economic quantitative studies on economic, quantitative, and environmental co-benefits are expected in order to provide more convincing costbenefit analysis.

\subsection{Improve institutional top-level design to effectively incorporate Co-benefit research results into decision-making}

Co-benefit studies touch energy, economics, environment, and many other fields. In order to effectively incorporate research results into decisionmaking, a top-level design of administrative institutions that facilitates the output of research results is needed, and the most important part of the design is strengthened coordination across departments. Intergovernmental coordination mechanism should be designed from three aspects of guideline, policy implementation and expert consultation. In terms of guideline, laws and regulations can be enacted to regulate and guide the behavior of the government and other social subjects. There are foreign references in this regard. For example, Bill for Energy and Water Research Integration Act of 2009 was adopted in the United States, requiring that water resources be integrated in energy research, development and demonstration projects. In terms of policy making, inter-ministerial committee, special task force and other organizations may be created to determine detailed policy planning and implementation stages under the guideline and to coordinate cooperation across government departments, between central and local governments, and between governments and scientific research institutions/enterprises. Given the actual situation in China, the National Energy Commission may list co-benefit matters in its priorities. In terms of expert consultation, a separate expert committee (or expert group) may be created or the existing Expert Committee on Climate Change may be relied upon to offer advice and recommendations on co-benefit matters.

\section{Conclusion}

China is now under the dual pressure of GHG reduction and environmental pollution control. Enriching cobenefit theories and practice is highly relevant and is consistent with the long-term environmental sustainable development strategy in China. Based on the research analysis and summary mentioned above, future cobenefit studies need to be expanded and improved. It is necessary to strengthen quantitative co-benefit studies. Firstly, the application and development of models should be strengthened, and the advantages of multiple models should be combined to break through the limitations of a single model. Secondly, more academic attention should be paid to the monetization of cobenefits in order to clarify environmental benefits, public health benefits, and social benefits and offer reference and comparability. Thirdly, innovative spirit is appreciated, and novel quantitative methods are encouraged in co-benefit evaluation. Last but not least, co-benefit studies on different regions and sectors should be consistently enhanced to keep enriching the depth and breadth of co-benefit theory and make it a mature theoretical system that can provide better scientific reference and basis for policy making at local and national levels.

\section{References}


1. Qilu Tan, Analysis on the co-benefits of reduction in greenhouse gas emissions from main sectors in China [D]. Beijing: Tsinghua University, 2015.

2. Intergovernmental Panel on Climate Change. Climate change 2001: Mitigation of climate changeContribution of Working Group III to the third assessment report of IPCC [M], Cambridge University Press, United Kingdom, 2001.

3. Qilu Tan, and Hongwei Yang. Co-benefit analysis of greenhouse gases and local air pollutants mitigation for transportation sector in BeijingTianjin-Hebei region, climate change, 2017, 39(4): 25-31.

4. Bollen J, Guay B, Jamet S, et al. Co-benefits of climate change mitigation policies: literature review and new results [R]. Paris: OECD Publishing, 2009.

5. EPA, Co-benefits definition [EB/OL], (2013-02-21), http://ofmpub.epa.gov/sor_internet/registry/termreg/ searchandretrieve/termsandacronyms/search.do?mat chCriteria $=$ Contains $\&$ checkedTerm $=$ on $\&$ checkedAc ronym $=$ on\&search $=$ Search \& term $=$ co-benefits.

6. EEA, What actions can be taken to reduce greenhouse gas emissions [EB/OL], (2007-12-10), http://www.eea.europa.eu/themes/climate/faq/whatactions-can-be-taken-to-reduce-greenhouse-gasemissions.

7. Overseas Environmental Cooperation Center, Cobenefits approach to climate change and $\mathrm{CDM}$ in developing countries [R], Tokyo, 2008.

8. Van Vuuren D P, Cofala J, Eerens H E, et al, Exploring the ancillary benefits of the Kyoto Protocol for air pollution in Europe[J], Energy Policy, 2006(4): 444-460.

9. Rypdal K, Rive N, Astrom S, et al, Nordic air quality co-benefits from European post-2012 climate policies[J], Energy Policy, 2007(12): 63096322.

10. Dudek D, Golub A, Strukova E, Ancillary benefits of reducing greenhouse gas emissions in transitional economies[J], World Development, 2003(10): 17591769.

11. Burtraw D, Krupnick A, Palmer K, et al, Ancillary benefits of reduced air pollution in the US from moderate greenhouse gas mitigation policies in the electricity sector $[\mathrm{J}$, Journal of Environmental Economics and Management, 2003(3): 650-673.

12. Dessus S, O'Connor D., Climate Policy without tears: CGE-based ancillary benefits estimates for Chile[J],Environmental and Resource Economics, 2003(3): 287-317.

13. Aunan K, Fang J H, Vennemo H, et al, Co-benefits of climate policy-lessons learned from a study in Shanxi, China[J],Energy Policy, 2004(4): 567-581.

14. Shih Y H, Tseng C H., Cost-benefit analysis of sustainable energy development using life-cycle cobenefits assessment and the system dynamics approach[J], Applied Energy, 2014(119): 57-66.
15. Bollen J, Van Der Zwaan B, Brink C, et al, Local air pollution and global climate change: A combined cost-benefits analysis[J], Resource and Energy Economics, 2009(3): 161-181.

16. Williams $\mathrm{C}$, Hasanbeigi $\mathrm{A}, \mathrm{Wu} \mathrm{G}$, et al, International Experience with Quantifying the CoBenefits of Energy Efficiency and Greenhouse Gas Mitigation Programs and Policies[J], Science and Management, 2013(3): 3-6.

17. Amann M, Bertok I, Borken Kleefeld J, et al, Costeffective control of air quality and greenhouse gases in Europe: modeling and policy applications[J], Environmental Modeling \& Software, 2011(12): 1489-1501.

18. Van Harmelen T, Bakker J, De Vries B, et al, Longterm reduction in costs of controlling regional air pollution in Europe due to climate change[J], Environmental Science \& Policy, 2002(4): 349-365.

19. Nathan R. Climate policy in Western Europe and avoided costs of air pollution control[J], Economic Modeling, 2010, 25(7): 1-13.

20. Alcamo J, Mayerhofer P, Guardans R, et al, An integrated assessment of regional air pollution and climate change in Europe: Findings of the AIRCLIM Project[J], Environmental Science \&Policy, 2002(4): 257-272.

21. Alcamo J, Shaw R, Hordijk L., The RAINS model of acidification: science and strategies in Europe[M], Dordrecht, Netherlands: Kluwer Academic Publishers, 1990.

22. Haidong, Kan and Bingheng Chen, Greenhouse gas mitigation policies and their ancillary effects [J], Journal of Environment and Health, 2001(5): 316318.

23. Yedla S, Park H. S., Co-benefit as an approach to align climate change concerns with national development objectives: solid waste management[J], Journal of Material Cycles and Waste Management, 2009(2): 123-129.

24. Shrestha R M, Pradhan S., Co-benefits of $\mathrm{CO} 2$ emission reduction in a developing country[J], Energy Policy, 2010(5): 2586-2597.

25. Anuan K, Patzay G, Asbjorn Aaheim H, et al, Health and environmental benefits from air pollution reduction in Hungary[J], Science of the Total Environment, 1998(2-3): 245-268.

26. Jochem E, Madlener R., The forgotten benefits of climate change mitigation: Innovation, technological leapfrogging, employment, and sustainable development[C], OECD Workshop on the Benefits of Climate Policy: Improving Information for Policy Makers, 2003.

27. Qilu Tan, Zongguo Wen, and Hongwei Yang. Review and recommendations on the co-benefit effects of controlling greenhouse gases and atmospheric pollutants, Environmental protection, 2018, 46(24):51-57. 
28. Bollen J.C., Van der Zwaan B., et al, Local air polluting and global climate change: a combined cost-benefit analysis[J], Resource and Energy Economics, 2009, 31(3): 161-181.

29. Petter Tollerfsen et al, Air pollution policies in Europe: efficiency gains from integrating climate effects with damage costs to health and crops[J], Environmental science and policy, 2009, 12(7): 870881.

30. Nathan Rive, Climate policy in Western Europe and avoided costs of air pollution control [J], Economic Modelling, 2010, 27(1): 103-115.

31. Peter Rafaj, Wolfgang Schopp, Peter Russ et al, Cobenefits of post-2012 global GHG-mitigation policies[J], Mitigation and Adaptation Strategies for Global Change, 2013, 18(6): 801-824.

32. Chae Y., Co-benefit analysis of an air quality management plan and greenhouse gas reduction strategies in the Seoul metropolitan area [J], Environmental Science and Policy, 2010, 13(3): 205:216.

33. Ram M. Shrestha, Shreekar Pradhan, Co-benefits of $\mathrm{CO} 2$ emission reduction in a developing country[J], Energy Policy, 2010, 38(5): 2586-2597.

34. Tao Hu, Chunxiu Tian, and Liping Li, Influence of co-benefit on policy in china [J], Environmental Protection, 2004(9): 56-58.

35. Liping Li, Guomei Zhou, and Haoyu Ji, Study of cobenefits assessment of pollution reduction: A case study in Panzhihua [J], China Population Resources and Environment, 2010, S2: 91-95.

36. Changhong Chen, and Bingyan Wang, Local air pollutant emission reduction and co-benefit of China energy policy: Shanghai case study [J], Shanghai Environmental Sciences, 2003(10): 682-689.

37. K. He, Y. Lei, X. Pan et al., Co-benefits from energy policies in China[J], Energy, 2010, 35(11): 4265-4272.

38. Yuanbo Xie, and Wei Li, Synergistic emission reduction of chief air pollutants and greenhouse gases based on scenario simulations of energy consumptions in Beijing [J], Environmental Science, 2013, 34(5): 2057-2064.

39. Xianqiang Mao, An Zeng, Tao Hu, et al., Study of coordinate control effect assessment of technological measures for emissions reduction [J], China Population Resources and Environment, 2011, 21(12):1-7. 